EGU2020-19514

https://doi.org/10.5194/egusphere-egu2020-19514

EGU General Assembly 2020

(c) Author(s) 2020. This work is distributed under

the Creative Commons Attribution 4.0 License.

\title{
Do different organic amendments effectively improve the soil biochemical activity of very poor arid soils from Tunisia?
}

\author{
Houda Oueriemmi ${ }^{1,2}$, Petra S Kidd ${ }^{1}$, Ángeles Prieto-Fernández ${ }^{1}$, Beatriz Rodriguez-Garrido ${ }^{1}$, \\ Mohamed Moussa ${ }^{2}$, and Carmen Trasar-Cepeda ${ }^{1}$ \\ ${ }^{1}$ Dept. Bioquímica del Suelo, IIAG-CSIC, Apartado 122, E-15780 Santiago de Compostela, Spain. \\ ${ }^{2}$ Arid Regions Institute, Medenine 4119, Tunisia
}

Soils from arid and semi-arid ecosystems are generally very low in organic matter content, poor in nutrients and typically with sandy texture. The application of different organic amendments has been proposed as an adequate approach to improve the quality of these soils for their use in agriculture. The use of organic wastes of different origins (agricultural, industrial, urban, etc.) as soil amendments has a dual goal: i) improving soil fertility and quality, ii) reducing the environmental problem that poses the disposal of these residues. However, despite of the beneficial effects of these residues, undesirable changes may also occur in agricultural soils after their addition. For example, the presence of various pollutants of anthropogenic origin in organic wastes may cause adverse effects on soil microbiota. Generally, the arid and semi-arid soils of Tunisia are well characterised. However, the use of organic amendments to improve the quality of these soils has been scarcely investigated. Soil biochemical properties, and specifically soil enzyme activities, have been often used to investigate the impact of different amendments on soil quality, because they are highly sensitive to human or environmental perturbations.

In this work, the results of a field trial established for investigating the effectiveness of three organic residues (composted municipal solid waste, composted sewage sludge and farmyard manure) to improve the quality of one agricultural soil from Tunisia are reported. The soil had a sandy texture, alkaline $\mathrm{pH}(\mathrm{pH} 8.3)$ and was very poor in organic matter $(0.21$ and $0.03 \%$ of total $\mathrm{C}$ and $\mathrm{N}$, respectively). Each of the organic residues was applied in triplicate at three different doses in nine sub-plots randomly distributed; three untreated sub-plots were also established for comparison. One, 6 and 18 months after the soil amendments, surface $(0-20 \mathrm{~cm})$ soil samples were collected from all the treated and untreated subplots. The soil samples were analysed for the enzyme activities of four hydrolases involved in the C, N, P and S cycles and for an oxidoreductase (dehydrogenase) reflecting soil microbial activity. All the soil samples were also characterised for their main physicochemical properties.

Addition of the three organic amendments induced slight increases of the total organic carbon and nutrients content; however, the improvements observed were generally not related with the amount of applied residue. The activity of the enzymes increased after the application of the three residues, but these increments were not correlated with the dose of residue and did not 
consistently varied with the time elapsed after residue application. Generally, the highest increases in absolute values were observed for manure-amended soils, but when the activities were considered in relation to the total organic $C$ of the soils, the sludge amended soils appeared to be the most favoured. The results are discussed with regards to their implications for improving very poor agricultural soils.

Acknowledgements: This research was financially supported by the Xunta de Galicia (IN607A 2017/6), UE Interreg-Sudoe program (SOE1/P5/E0189) and the Tunisian Ministry of Higher Education and Scientific Research. H. Oueriemmi thanks founding support of Erasmus plus program for her stay at the IIAG-CSIC. 